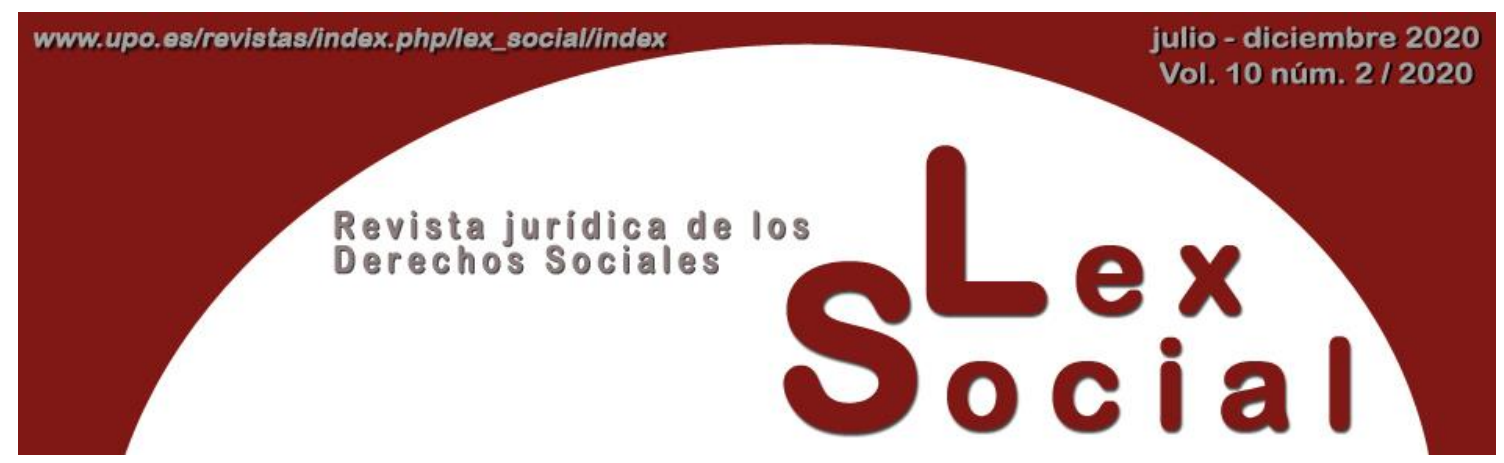

\title{
LAS LÍNEAS DIRECTRICES DE LA OCDE PARA EMPRESAS MULTINACIONALES Y SU PUESTA EN PRÁCTICA POR LOS PUNTOS NACIONALES DE CONTACTO ${ }^{1}$
}

\section{THE OECD GUIDELINES FOR MULTINATIONAL ENTERPRISES AND THEIR IMPLEMENTATION BY THE NATIONAL CONTACT POINTS}

\author{
SILVIA FERNÁNDEZ MARTÍNEZ \\ Investigadora Postdoctoral \\ Área de Derecho del Trabajo y de la Seguridad Social \\ Universidad de Alcalá ${ }^{2}$
}

Artículo recibido el 21 de mayo de 2020

Artículo aceptado el 3 de junio de 2020

DOI: https://doi.org/10.46661/lexsocial.5066

\section{RESUMEN}

Las Líneas Directrices de la OCDE para empresas multinacionales son uno de los instrumentos que han tratado el tema de las empresas multinacionales en el plano internacional. Ofrecen una serie de recomendaciones dirigidas a promover una conducta responsable y en línea con las normas internacionales por parte de dichas empresas. Las Directrices pertenecen al ámbito del soft law, tanto en relación con los sujetos receptores activos - los países adherentes- como con los pasivos - las empresas multinacionales. No crean obligaciones jurídicas para las empresas

\footnotetext{
${ }^{1}$ Este trabajo se ha elaborado en el marco del proyecto de investigación "Empresas multinacionales y normas internacionales del trabajo. Especial referencia a la situación de España" (DER2016-77973-R), cuyo Investigador Principal es el profesor José Luis Gil y Gil. Una primera versión se presentó en el seminario internacional "Responsabilidad de las empresas multinacionales por vulneración de los estándares laborales: Entre lo deseable y lo posible", celebrado en la Universidad de Alcalá el 16 de diciembre de 2019.

Principales abreviaturas utilizadas: OCDE (Organización para la Cooperación y el Desarrollo Económicos), OIT (Organización Internacional del Trabajo), ONU (Organización de las Naciones Unidas), PNC (Punto Nacional de Contacto).

${ }^{2}$ Programa de Atracción del Talento Investigador a Grupos de Investigación de la Comunidad de Madrid.
} 
multinacionales y tampoco prevén mecanismos de responsabilidad en caso de incumplimiento. Los Estados adherentes se comprometen a promover su uso y a establecer Puntos Nacionales de Contacto, pero las Directrices tampoco les imponen ningún tipo de responsabilidad si no respetan su compromiso. La particularidad de este instrumento radica en que prevé una serie de procedimientos para su puesta en práctica, entre los que destaca el tratamiento de casos específicos por los Puntos Nacionales de Contacto, que contribuirán a resolver las quejas que se plantean acerca del posible incumplimiento de las Directrices por las empresas multinacionales. Pese a su carácter no vinculante, las Líneas Directrices de la OCDE para empresas multinacionales pueden servir como base o guía para la elaboración de normas jurídicamente vinculantes en el futuro.

Palabras Clave: empresas multinacionales, Líneas Directrices OCDE, Puntos Nacionales de Contacto, responsabilidad social corporativa.

\begin{abstract}
The OECD Guidelines for multinational enterprises are one of the instruments that have dealt with the issue of multinational enterprises at international level. The Guidelines offer a set of recommendations to multinational enterprises aimed at promoting responsible conduct consistent with applicable laws and internationally recognised standards. The Guidelines belong to the field of soft law, both in relation to the active recipients - the adhering countries - and to the passive ones multinational enterprises. They do not create legal obligations for multinational enterprises, nor do they provide liability mechanisms in case of non-compliance. The adhering countries undertake to promote its use and to set up National Contact Points, but the Guidelines do not impose any type of responsibility on them if they do not respect their commitment. The distinctive feature of this instrument lies in the fact that it foresees a series of procedures for its implementation. National Contact Points contribute to the resolution of issues that arise relating to the implementation of the Guidelines in specific instances. Despite their non-binding nature, the OECD Guidelines for multinational enterprises can be used as a basis or guide for the development of legally binding standards in the future.
\end{abstract}

KEYWORDS: multinational enterprises, OECD Guidelines, National Contact Points, corporate social responsibility.

SUMARIO

I. Introducción.

II. Origen y evolución de las Líneas Directrices la OCDE para empresas multinacionales.

III. Naturaleza, ámbito subjetivo y responsabilidad por incumplimiento de las Líneas

Directrices.

IV. Los capítulos sobre derechos humanos y sobre empleo y relaciones laborales. 

el Comité de Inversión.

\section{Conclusiones.}

Bibliografía

Anexo

\section{Introducción}

Según la concepción tradicional, las empresas multinacionales no tienen la condición de sujetos de derecho internacional. En concreto, el derecho internacional del trabajo se dirige a los Estados y no las empresas multinacionales. Sin embargo, la comunidad internacional se ha esforzado por lograr el objetivo de una conducta empresarial responsable en un mundo globalizado y, para ello, se han adoptado otros instrumentos ${ }^{3}$. Las Líneas Directrices de la OCDE para empresas multinacionales son, junto con la Declaración tripartita de principios sobre las empresas multinacionales y la política social de la OIT y los Principios rectores sobre las empresas y los derechos humanos de la ONU, uno de los instrumentos que han abordado la cuestión de las empresas multinacionales en el ámbito internacional. Mientras que los Principios Rectores de la ONU se centran en los derechos humanos y la Declaración tripartita de la OIT lo hace en los estándares laborales, las Líneas Directrices de la OCDE constituyen un marco de referencia más amplio, pues además de aquellos, también tratan otras materias, como el medio ambiente o la lucha contra la corrupción.

La principal dificultad con la que nos topamos cuando nos aproximamos al estudio de las empresas multinacionales es la ausencia de un concepto unívoco de tales empresas en el ámbito internacional. De hecho, ni la OIT en su Declaración tripartita, ni la OCDE en las Líneas Directrices ofrecen una definición de qué ha de entenderse por "empresas multinacionales". En el Capítulo dedicado a los "Conceptos y Principios", las Directrices de la OCDE aclaran que "no es necesaria a los efectos de las Directrices una definición precisa de empresas multinacionales". Las empresas a las que se dirigen las Directrices son aquellas que actúan, de alguna manera, fuera del país en el que tienen su sede, ya sea porque producen, son propietarias de medios de producción o controlan la producción que se realiza en un país tercero. Tanto la OIT como la OCDE son conscientes de que la ausencia de un concepto específico de empresas multinacionales puede llegar a generar importantes incertidumbres, pero no quieren que la Declaración y las Directrices queden

\footnotetext{
${ }^{3}$ GIL Y GIL, José Luis, "Globalización y universalidad del derecho: la lex mercatoria y el derecho internacional del trabajo en el mercado global", Revista Internacional y Comparada de Relaciones Laborales y Derecho del Empleo, 2016, n 2, pp. 19 ss., y "La dimensión social de la globalización en los instrumentos de la OIT", Revista Internacional y Comparada de Relaciones Laborales y Derecho del Empleo, 2017, no 1, pp. 29 ss.
} 
sin aplicarse por este motivo ${ }^{4}$. A nivel doctrinal, se utiliza tanto la expresión empresas multinacionales como empresas transnacionales y, aunque puede haber diferencias entre ambos conceptos, pues algunos autores los distinguen, en la mayoría de las ocasiones se usan de manera indistinta ${ }^{5}$.

En los últimos años, el tema de la responsabilidad de las empresas multinacionales por vulneración de los derechos humanos ha sido objeto de notable atención en el ámbito internacional, sobre todo desde la adopción de los Principios Rectores de la ONU. Ahora bien, no hay que olvidarse de los otros dos instrumentos que también se ocupan de la conducta responsable de las empresas multinacionales. En este trabajo, nos concentraremos en las Líneas Directrices de la OCDE. Aunque se adoptaron hace más de 40 años, cabe plantearse si son todavía actuales y si aún sirven para cumplir los objetivos que motivaron su creación. Con ocasión de su 40 aniversario, se celebró en París una mesa redonda en la que se trataron estas y otras cuestiones, y se otorgó especial importancia al debate sobre cómo deberían ser los próximos 40 años de vigencia de las Líneas Directrices ${ }^{6}$.

En un artículo en el que analizaba la transcendencia de las Líneas Directrices de la OCDE 20 años después de su adopción, BLANPAIN apuntaba que, debido al enorme avance de la inversión internacional en la década de los 90, los objetivos y el espíritu de las Directrices eran más relevantes entonces de lo que lo habían sido en el momento de su creación ${ }^{7}$. En esta línea, teniendo en cuenta que los cambios en el mercado internacional han sido todavía mayores en los últimos 20 años, cabe analizar si dicha relevancia sigue estando vigente.

\section{Origen y evolución de las Líneas Directrices de la OCDE para empresas multinacionales}

Las Líneas Directrices de la OCDE para empresas multinacionales se adoptaron el 21 de junio de 1976. Desde entonces, la actividad empresarial internacional ha experimentado importantes cambios. En consecuencia, las Directrices se han revisado en varias ocasiones con el objetivo de reflejarlos ${ }^{8}$. Su última versión, en la que nos centraremos en el presente trabajo, es del año $2011^{9}$.

\footnotetext{
4 JIMÉNEZ SÁNCHEZ, José Joaquín, "Marcos de las relaciones laborales en las empresas multinacionales: las directrices de la OCDE", Cuadernos de derecho judicial, 2005, n 17, p. 43.

5 Para un análisis detallado de las distintas posturas doctrinales sobre el concepto de empresas multinacionales véase: JIMÉNEZ SÁNCHEZ, José Joaquín, op. cit., p. 39 y ss.

${ }^{6}$ La mesa redonda Forty years of the OECD Guidelines for multinational enterprises tuvo lugar en París el 19 de diciembre de 2016. En el siguiente link, puede consultarse el programa: http://mneguidelines.oecd.org/roundtable-40-years-of-the-guidelines-agenda.pdf

${ }^{7}$ BLANPAIN, Roger, "Guidelines for Multinational Enterprises, for Ever? The OCDE Guidelines, 20 years later", The International Journal of Comparative Labour Law and Industrial Relations, 1998, vol. 14, $\mathrm{n}^{\circ} 4$, p. 345.

${ }^{8}$ En concreto, en 1979, 1982, 1984, 1991, 2000 y 2011.

${ }^{9}$ https://www.oecd.org/daf/inv/mne/MNEguidelinesESPANOL.pdf
} 
La OCDE fue pionera en la creación de un instrumento internacional dirigido a las empresas multinacionales, pues la primera versión de las Líneas Directrices para empresas multinacionales es incluso anterior a la Declaración tripartita de principios sobre las empresas multinacionales y la política social, adoptada por el Consejo de Administración de la Oficina Internacional del Trabajo en su 204ª reunión, en noviembre de $1977^{10}$. En general, las Directrices tuvieron una buena acogida y, en aquel momento, se consideraron un paso adelante muy importante en el proceso de elaboración de un código de conducta general para las empresas multinacionales. De hecho, fueron el primer código de conducta voluntario que incluía a países desarrollados ${ }^{11}$. Aunque, en un primer momento, recibieron críticas por parte del movimiento sindical, acabaron considerándolas un hito en el proceso internacional de regulación de las empresas multinacionales.

Las Directrices forman parte del paquete de disposiciones de la Declaración de la OCDE sobre inversión internacional y empresas multinacionales. Por lo general, los instrumentos legales que la OCDE tiene a su disposición se dirigen a los Estados o a las organizaciones internacionales, pero no a los actores privados, como las empresas multinacionales. Por lo tanto, se ha considerado que esta Declaración no forma parte de los instrumentos tradicionales de la $\mathrm{OCDE}^{12}$, sino que constituye un compromiso político de sus Estados parte, para mejorar el ámbito de las inversiones, alentar la contribución de las empresas multinacionales al progreso económico y social, y reducir y resolver las dificultades que surgieran como resultado de sus operaciones ${ }^{13}$. Aunque también se refiere a otros aspectos, como el trato nacional, las obligaciones contradictorias impuestas a las empresas y los incentivos y desincentivos a la inversión internacional, las Directrices para las empresas multinacionales son, sin duda, el elemento más importante de la Declaración sobre inversión internacional y empresas multinacionales.

$\mathrm{La}$ OCDE es un foro de encuentro intergubernamental que tiene un claro enfoque económico. Su vocación principal es la de facilitar la inversión y el crecimiento del comercio mundial. Cabe plantearse, entonces, por qué una organización internacional de estas características consideró necesario expandir su ámbito de actuación y elaborar unas pautas de conducta dirigidas a las empresas multinacionales, en un momento en el que la responsabilidad social de las empresas todavía no estaba en el debate público. La doctrina entiende que sus razones están relacionadas con el contexto político que precedió a la adopción de las Directrices. En aquella época, la imagen pública de las empresas multinacionales se estaba viendo deteriorada debido a la implicación de algunas de ellas

10 emp_ent/documents/publication/wcms_124924.pdf

https://www.ilo.org/wcmsp5/groups/public/---ed_emp/---

${ }^{11}$ VAN'T FOORT, Sander, "The History of National Contact Points and the OECD Guidelines for Multinational Enterprises", Rechtsgeschichte-Legal History, 2017, nº 25, p. 197.

${ }^{12}$ VAN'T FOORT, Sander, op. cit., p. 197.

${ }^{13}$ CANTÚ RIVERA, Humberto, "La OCDE y los derechos humanos: el caso de las Directrices para Empresas Multinacionales y los Puntos de Contacto Nacional", Anuario Mexicano de Derecho Internacional, 2015, vol. XV, p. 619. 
en ciertos conflictos políticos, como el golpe de estado en Chile, y a su vinculación con Estados que violaban los derechos humanos ${ }^{14}$.

Las Líneas Directrices de la OCDE se adoptaron en un momento histórico particular, cuando, en el seno de la ONU, se estaba empezando a reflexionar sobre la necesidad de crear un Nuevo Orden Económico Internacional, que integrase la participación de los nuevos países independientes que habían surgido en las décadas de los sesenta y setenta. Aquellos países disponían de muchos recursos nacionales, pero contaban con escasa participación en la economía y políticas internacionales. El objetivo que se perseguía era limitar y regular las actividades de las empresas multinacionales, con la finalidad de proteger la economía de los países en los que operaban, que eran, en su mayoría, países en vías de desarrollo ${ }^{15}$. En concreto, en el año 1974, la ONU elaboró una Declaración sobre el Nuevo Orden Económico Internacional y puso en marcha un proyecto para elaborar un código de conducta para las empresas multinacionales. Sin embargo, este proyecto se abandonó en 1992, porque no se logró alcanzar un consenso entre los Estados. Al mismo tiempo que empezaba dicho debate en el ámbito de la ONU, los miembros de la OCDE iniciaron su propio proceso en torno a la actuación de las empresas multinacionales ${ }^{16}$. En concreto, dos años después del inicio de las actividades en el seno de la ONU, la OCDE adoptó sus Líneas Directrices para empresas multinacionales ${ }^{17}$.

Desde su adopción en 1976, las Líneas Directrices, al igual que las propias empresas multinacionales, han pasado por distintas fases ${ }^{18}$. En su etapa inicial, durante sus primeros 10 años de existencia, tuvieron cierta fuerza, sobre todo en el campo sindical y de las ONG. Sin embargo, en la siguiente fase, entre mediados de los años 80 y finales de los 90, las Directrices estuvieron prácticamente inactivas. En aquella época, aparecieron los códigos de conducta empresariales que, por lo general, tenían carácter interno y se establecían de forma unilateral por las empresas, y las primeras políticas de responsabilidad social empresarial o corporativa. Todas estas iniciativas pretendían luchar contra la mala imagen que estaban adquiriendo algunas empresas multinacionales, debido a las malas prácticas que habían llevado a cabo. A finales de la década de los noventa, en concreto en 1998, cuando fracasaron las negociaciones del Acuerdo Multilateral sobre Inversiones (AMI), las Directrices, pero también la OCDE, experimentaron su peor momento. En aquel contexto, la OCDE decidió relanzar las Líneas Directrices para empresas multinacionales y realizar una nueva revisión.

La revisión del año 2000 marcó el inicio de la tercera etapa de las Directrices. Esta es, junto con la del año 2011, la modificación más importante que han experimentado. Uno de los cambios más relevantes fue el relacionado con su ámbito de aplicación. Las Líneas

\footnotetext{
${ }^{14}$ DAUGAREILH, Isabelle, "La dimension sociale des principes directeurs de l'O.C.D.E. à l'intention des entreprises multinationales”, Revue generale de droit international public, 2008, vol. 112, no 3, p. 568.

${ }^{15}$ CANTÚ RIVERA, Humberto, op. cit., p. 618.

${ }^{16}$ CANTÚ RIVERA, Humberto, op. cit., p. 619.

17 Véase DAUGAREILH, Isabelle, "La dimension sociale...", op. cit., p. 568.

${ }^{18}$ Para un análisis en profundidad de la evolución de las Directrices, véase JIMÉNEZ SÁNCHEZ, José Joaquín, op. cit., p. 66 y ss.; y MURRAY, Jill, “A New Phase in the Regulation of Multinational Enterprises: The Role of the OECD”, Industrial Law Journal, 2001, vol. 30, n 3, pp. 255-270.
} 
Directrices pasaron de resultar aplicables solo en los establecimientos de las empresas multinacionales ubicados en los países que las habían suscrito o que se habían adherido a las mismas, a serlo también a cualquiera de sus entidades, en cualquier lugar en el que se hallen establecidas, así como a las empresas y socios comerciales de las empresas multinacionales y de las cadenas de suministro. Por otro lado, en dicha revisión también se introdujo un mecanismo para dar seguimiento a las quejas respecto a la puesta en práctica de las Directrices ${ }^{19}$, que trajo consigo una mayor actividad de los distintos gobiernos en relación con las Líneas Directrices. Además, también se incorporaron, por primera vez, referencias expresas a los derechos humanos.

La actividad empresarial internacional experimentó un cambio estructural de gran alcance en la primera década del siglo XXI, es decir, desde la actualización de las Líneas Directrices del año $2000^{20}$. En consecuencia, el día 4 de mayo de 2010, los gobiernos de 42 países miembros y no miembros de la OCDE, adherentes a la Declaración de la OCDE sobre inversión internacional y empresas multinacionales y a la Decisión conexa, comenzaron a trabajar en la actualización de las Directrices, con el objetivo de que reflejasen dichos cambios ${ }^{21}$.

En 2011, se produjo un hito en el seno de la ONU, que tuvo una influencia muy importante en el proceso de actualización de las Líneas Directrices de la OCDE. El 21 de marzo de 2011, el Representante Especial del Secretario General para la cuestión de los derechos humanos y las empresas transnacionales y otras empresas, John Ruggie, elaboró los Principios rectores sobre las empresas y los derechos humanos, que adjuntó a su informe al Consejo de Derechos Humanos ${ }^{22}$. Posteriormente, el Consejo de Derechos Humanos adoptó los Principios rectores sobre las empresas y los derechos humanos: puesta en práctica del marco de las Naciones Unidas para "proteger, respetar y remediar", en su resolución 17/4 de 16 de junio de $2011^{23}$. La doctrina interpreta que los Principios rectores de la ONU sobre empresas y derechos humanos fueron la base para la reforma de las Directrices de la OCDE para empresas multinacionales ${ }^{24}$. Uno de los pilares en los que se basan los Principios rectores de la ONU, y que más nos interesan a estos efectos, es la necesidad de un mayor acceso a recursos jurídicos y no jurídicos que permitan remediar adecuadamente, y de forma integral, los daños sufridos por las víctimas de tales violaciones.

\footnotetext{
${ }^{19}$ CANTÚ RIVERA, Humberto, op. cit., p. 624.

${ }^{20}$ Entre los cambios que menciona el Prefacio de las Líneas Directrices, destacan el desarrollo del sector servicios, de las actividades basadas en el conocimiento y la expansión de la economía por Internet. En este contexto, las empresas de servicios y tecnología juegan un papel cada vez más importante en el mercado internacional. Además, ha registrado un rápido crecimiento la inversión de las empresas multinacionales, que además han diversificado sus actividades en los países en desarrollo.

${ }^{21}$ Para actualizar las Directrices, la OCDE buscó el consenso y también la especialización. En relación con el primero, se realizó una mesa redonda de consultas con las partes interesadas. También se quiso actuar de manera conjunta con otras organizaciones internacionales y, de hecho, el Representante Especial del Secretario General de la ONU para los derechos humanos y las empresas y la OIT efectuaron contribuciones relevantes.

${ }^{22} \mathrm{~A} / \mathrm{HRC} / 17 / 31$.

${ }^{23}$ https://www.ohchr.org/documents/publications/guidingprinciplesbusinesshr_sp.pdf

${ }^{24}$ CANTÚ RIVERA, Humberto, op. cit., p. 628.
} 
El proceso de actualización de las Líneas Directrices de la OCDE para empresas multinacionales culminó el 25 de mayo de 2011, cuando las Directrices actualizadas y la Decisión conexa fueron adoptadas por los 42 gobiernos adherentes en la Reunión Ministerial conmemorativa del 50 aniversario de la OCDE. En la revisión de 2011, se realizaron una serie de modificaciones en las Directrices que pretendían garantizar su continuidad como instrumento internacional principal para la promoción de conductas empresariales responsables. Estos cambios fueron tan significativos que algunos autores han apuntado que, de cierta forma, esta última revisión de las Directrices constituyó una revisión integral de las mismas ${ }^{25}$. Entre los cambios más importantes, destacan los siguientes: se añadió un nuevo capítulo sobre derechos humanos, acorde con los Principios rectores de la ONU sobre empresas y derechos humanos; se utilizó un enfoque nuevo y amplio en relación con el principio de la debida diligencia y con la gestión responsable de la cadena de suministro; se incorporaron cambios sustanciales en numerosos capítulos especializados, entre ellos en el de empleo y relaciones laborales; y se incluyó una guía de procedimiento más clara y más estricta para fortalecer el papel de los Puntos Nacionales de Contacto (PNC) en la puesta en práctica de las Directrices.

\section{Naturaleza, ámbito subjetivo y responsabilidad por incumplimiento de las Líneas Directrices}

La Declaración sobre inversión internacional y empresas multinacionales de la OCDE se estructura de la siguiente manera. Después del texto de la propia Declaración, en la Parte I se recogen las "Líneas Directrices de la OCDE para Empresas Multinacionales. Recomendaciones para una conducta empresarial responsable en el contexto global". Esta primera parte consta de un Prefacio y de 11 capítulos sobre los siguientes aspectos: conceptos y principios, principios generales, divulgación de información, derechos humanos, empleo y relaciones laborales, medio ambiente, lucha contra la corrupción, intereses de los consumidores, ciencia y tecnología, competencia, cuestiones tributarias. La Parte II se dedica a los "Procedimientos para la implementación de las Líneas Directrices de la OCDE para Empresas Multinacionales". A continuación, aparece la Enmienda a la Decisión del Consejo sobre las Líneas Directrices de la OCDE para empresas multinacionales, que versa sobre los Puntos Nacionales de Contacto y sobre el Comité de Inversión, y la Guía de Procedimiento. En último lugar, está el Comentario sobre los procedimientos de implementación. Aunque el índice menciona de manera expresa los comentarios solo en la Parte II, también están presentes en la primera parte, después de cada uno de los Capítulos. El Comité de Inversiones adoptó los comentarios sobre las Líneas Directrices en una sesión ampliada, en la que se incluyó a los ocho países no miembros adherentes a la Declaración, con el fin de proporcionar información y aclaraciones sobre el texto de las Líneas Directrices y de la Decisión del Consejo sobre dichas Directrices. Sin embargo, dichos comentarios no forman parte de la Declaración ni de la Decisión del Consejo.

\footnotetext{
${ }^{25}$ CANTÚ RIVERA, Humberto, op. cit., p. 614.
} 
Las Líneas Directrices cuentan con un capítulo que se titula "Conceptos y Principios", en el que se definen a sí mismas como "recomendaciones dirigidas conjuntamente por los gobiernos a las empresas multinacionales". Las Directrices "contienen principios y normas ${ }^{26}$ de buenas prácticas". Ahora bien, cabe señalar que, mientras que la mayoría de las disposiciones recogidas en las Líneas Directrices adopta la forma de recomendaciones, la Decisión del Consejo relativa a las Líneas Directrices de la OCDE para empresas multinacionales tiene carácter vinculante para los Estados adherentes.

Desde el punto de vista subjetivo, las Directrices afectan a cuatro categorías de sujetos: un sujeto emisor -la OCDE-, unos receptores activos - los gobiernos adherentes-, unos receptores pasivos - las empresas multinacionales- y un sujeto beneficiario - las sociedades- ${ }^{27}$.

Los sujetos receptores activos son los gobiernos, tanto los de los países miembros de la OCDE como los de otros que, aun sin ser miembros de la citada organización, se adhirieron de manera voluntaria a las Directrices ${ }^{28}$. Aunque los destinatarios últimos de las Líneas Directrices son las empresas multinacionales, al no ser sujetos de derecho internacional, quienes se adhieren a las mismas son los Estados y no las citadas empresas.

Tal y como se señala en el Prefacio de las Directrices, el objetivo común de los gobiernos que elaboran o se adhieren a las mismas "consiste en impulsar las contribuciones positivas que las empresas multinacionales pueden realizar al progreso económico, medioambiental y social, y en reducir al mínimo las dificultades que puedan causar sus diversas actividades". El fin último que persiguen es la mejora del bienestar y de los niveles de vida de todos los ciudadanos, es decir, del sujeto beneficiario -la sociedad.

Los países adherentes se comprometen a poner en práctica las Directrices y a promover su uso, tal y como queda plasmado en la Decisión del Consejo. Con este fin, deberán,

\footnotetext{
${ }^{26}$ Las Líneas Directrices aclaran que, en algunos países, como Colombia y México, se utiliza la expresión "estándares" para referirse a este tipo de normas no vinculantes. Véase la página 3 de las Líneas Directrices: "En dichos países, el término "norma" se emplea más bien en su acepción de "precepto jurídico" (ley, regla u orden). No obstante, en la versión española de las Directrices se ha optado por utilizar "norma" también con el primer significado mencionado, acorde con la primera acepción que propone el Diccionario de la Real Academia Española para dicho término ("Regla que se debe seguir o a que se deben ajustar las conductas, tareas, actividades, etc."). El sustantivo "estándar", aunque figura en dicho diccionario con el significado de "tipo, modelo, patrón, nivel", se considera un anglicismo (standard) en la acepción que tiene en las Directrices". Ahora bien, en el presente trabajo también se utilizará el término "estándares", en particular "estándares laborales".

${ }^{27}$ JIMÉNEZ SÁNCHEZ, José Joaquín, op. cit., p. 82 y ss.

28 A fecha de 25 de mayo de 2011, los gobiernos adherentes a las Directrices, además de los países miembros de la OCDE, eran Argentina, Brasil, Egipto, Letonia, Lituania (el 2 de diciembre de 2019, Letonia y Lituania también entraron a formar parte de la OCDE), Marruecos, Perú y Rumania. El 29 de mayo de 2020, se han adherido a las Directrices 49 países de todo el mundo, entre ellos los 37 miembros de la OCDE (Alemania, Australia, Australia, Bélgica, Canadá, Chile, Colombia, República Checa, Corea, Dinamarca, Estados Unidos, Estonia, Finlandia, Francia, Grecia, Hungría, Islandia, Irlanda, Israel, Italia, Japón, Letonia, Lituania, Luxemburgo, México, Holanda, Nueva Zelanda, Noruega, Polonia, Portugal, Eslovaquia, Eslovenia, España, Reino Unido, Suecia, Suiza, Turquía) y otros 12 países no miembros (Argentina, Brasil, Costa Rica, Croacia, Egipto, Jordania, Kazajistán, Marruecos, Perú, Rumanía, Túnez, Ucrania). Cfr. https://www.oecd.org/daf/inv/mne/oecddeclarationanddecisions.htm.
} 
entre otras cosas, establecer Puntos Nacionales de Contacto (infra $V)^{29}$. Ahora bien, aunque las previsiones recogidas en la Decisión del Consejo tienen carácter vinculante para los Estados, las Directrices no prevén ningún tipo de responsabilidad para aquellos que no cumplan con el compromiso que han adquirido. La mayoría de la doctrina interpreta que los códigos de conducta que promueven no tienen eficacia obligatoria ni carácter vinculante en el plano interestatal, sino que se limitan a ofrecer unas pautas de comportamiento que los sujetos destinatarios pasivos - las empresas multinacionales-, pueden decidir cumplir o no ${ }^{30}$. Por lo tanto, puede decirse que las Directrices solo imponen una responsabilidad moral a los Estados que no cumplen con las obligaciones que les imponen ${ }^{31}$. Además, el hecho de formar parte de la Declaración sobre inversión internacional y empresas multinacionales afecta al propio estatus de las Líneas Directrices. Algunos autores apuntan que la expresión "Directrices" (Guidelines) puede llevar a confusión, ya que, en realidad, al no imponer responsabilidad jurídica a los países adherentes, las Directrices también tienen la naturaleza de una Declaración ${ }^{32}$.

En cuanto a los sujetos receptores pasivos -las empresas multinacionales-, las Líneas Directrices no se dirigen a todas ellas, sino solo a las que llevan a cabo su actividad, o tienen su sede, en países que se han adherido a las Líneas Directrices, puesto que no tienen carácter universal ${ }^{33}$. Aun así, su ámbito de cobertura en la práctica es muy amplio, pues pueden aplicarse en cualquier país adherente en el que una multinacional actúe, tenga su sede o relaciones con proveedores, suministradores o distribuidores. En consecuencia, las Directrices juegan un papel muy importante en las cadenas de suministro.

En relación con la responsabilidad que imponen a las empresas multinacionales, en varias ocasiones, ya en el prólogo, pero también en la propia definición, se deja claro que "el cumplimiento de las Directrices por parte de las empresas es voluntario y no es jurídicamente vinculante". Se trata de recomendaciones que representan expectativas de comportamiento por parte de las empresas, pero su alcance jurídico es mínimo y tienen una coercibilidad únicamente moral. No crean obligaciones jurídicas en sentido estricto ni imponen sanciones en caso de incumplimiento por parte de las empresas

\footnotetext{
${ }^{29}$ La OCDE elabora un informe anual en el que analiza las acciones que han llevado a cabo los distintos países para poner en práctica las Directrices sobre empresas multinacionales. Véase, el más reciente: OECD, Annual Report on the OECD Guidelines for Multinational Enterprises 2018, 2019. Disponible en: https://www.oecd.org/daf/inv/mne/annualreportsontheguidelines.htm

${ }^{30}$ Alude a esa interpretación mayoritaria GIL Y GIL, José Luis, "Globalización y universalidad del derecho: la lex mercatoria y el derecho internacional del trabajo en el mercado global", op. cit., pp. 23 y 34, y "La dimensión social de la globalización en los instrumentos de la OIT", op. cit., pp. 29 y 30 . El autor citado entiende que, aun así, "no puede minusvalorarse la relevancia jurídica de los mecanismos de autolimitación y autodisciplina de las empresas multinacionales, que contribuyen a la consecución privada de intereses de índole colectiva, y que, a veces, se hallan sometidos a la certificación voluntaria de entes privados, en general transnacionales, tales como Social Accountability International (SAI) o Fair Labor Association (FLA)".

31 VAN'T FOORT, Sander, op. cit., p. 198.

${ }^{32}$ VAN'T FOORT, Sander, op. cit., p. 198.

${ }^{33}$ Por ejemplo, no se dirigen a una empresa con sede en China y que opera en Vietnan, porque ninguno de los dos países se ha adherido a las Directrices.
} 
multinacionales. Por lo tanto, aunque en ocasiones se expresen en términos imperativos ${ }^{34}$, no dan lugar a ninguna sanción en caso de las empresas no respeten lo que establecen las Directrices.

En conclusión, desde el punto de vista de la responsabilidad, las Líneas Directrices de la OCDE para empresas multinacionales constituyen un instrumento de soft law, tanto en relación con los sujetos receptores activos - los países adherentes- como con los pasivos - las empresas multinacionales.

Las Líneas Directrices de la OCDE para empresas multinacionales forman parte de los denominados mecanismos voluntarios de responsabilidad social corporativa $\mathrm{o}$ responsabilidad social empresarial. Constituyen la expresión práctica de dicho concepto, pues no son legalmente exigibles ${ }^{35}$. Aunque surgieron mucho antes de que empezase dicho movimiento, en realidad, en un primer momento pasaron desapercibidas, y no tuvieron repercusión hasta que se desarrolló la corriente de la responsabilidad social de las empresas ${ }^{36}$.

Los códigos de conducta para las empresas multinacionales pueden ser de distintos tipos en función de su origen: estatal, interestatal, no estatal e individuales. En concreto, las Líneas Directrices de la OCDE, junto con otros como la Declaración tripartita de la OIT, pertenecen al grupo de los mecanismos interestatales ${ }^{37}$. Dada la ausencia, por el momento, de otros instrumentos coercitivos dirigidos a las empresas multinacionales, este tipo de instrumentos son los únicos que, en el ámbito internacional, intentan promover que aquellas respeten los derechos humanos.

Por otro lado, las Directrices también apuntan que las normas y principios que recogen son "conformes con las disposiciones legales aplicables y otras normas reconocidas internacionalmente". En consecuencia, están reconociendo que algunos de los temas que abordan pueden estar sujetos a leyes nacionales o a compromisos internacionales. Sin embargo, en estos casos, serán obligatorios en la medida en que están previstos en esos otros instrumentos, pero su exigibilidad no puede derivar, en ningún caso, de su inclusión en las Directrices. Esto ha llevado a la doctrina a sostener que las Directrices tienen una naturaleza híbrida, pues no son una norma jurídica, pero, en ocasiones, reflejan cuestiones que sí están cubiertas por normas legales ${ }^{38}$.

La naturaleza no vinculante de las Líneas Directrices para empresas multinacionales ha planteado dudas en torno a su verdadera eficacia. En este sentido, se han desarrollado dos corrientes contrapuestas ${ }^{39}$.

\footnotetext{
${ }^{34}$ Las Directrices alternan expresiones como "las empresas deberán” con otras como "se alienta a las empresas a que".

${ }^{35}$ CANTÚ RIVERA, Humberto, op. cit., p. 622.

36 DAUGAREILH, Isabelle, "Responsabilidad social de las empresas transnacionales: análisis crítico y prospectiva jurídica", Cuadernos de Relaciones Laborales, 2009, n 1, p. 84.

37 GIL Y GIL, José Luis, "Globalización y universalidad del derecho: la lex mercatoria y el derecho internacional del trabajo en el mercado global", op. cit., p. 23, y "La dimensión social de la globalización en los instrumentos de la OIT", op. cit., pp. 28 y 29.

${ }^{38}$ VAN'T FOORT, Sander, op. cit., p. 209.

${ }^{39}$ Para una reconstrucción de ambas posturas, véase CANTÚ RIVERA, Humberto, op. cit., p. 636 y ss. 
Por un lado, su carácter voluntario o no vinculante es uno de los principales motivos de crítica a las Directrices. Ahora bien, esta es una característica propia del ámbito de la responsabilidad de las empresas en el ámbito internacional. Los defensores de esta postura señalan que la concepción de las Directrices como una disposición voluntaria las convierte en opcionales, lo que reduce su eficacia y aplicación. En consecuencia, para ser realmente eficaces, las Directrices deberían convertirse en normas jurídicas de derecho internacional directamente aplicables a las empresas multinacionales. Sin embargo, esta parece una posibilidad remota ${ }^{40}$.

Por otro lado, también cabría entender que el hecho de que no sean vinculantes, no quiere decir que no sean relevantes ${ }^{41}$. Para algunos autores, la importancia y el éxito de las Líneas Directrices radica, precisamente, en su flexibilidad, pues ofrecen pautas de comportamiento a las empresas sobre lo que sería socialmente esperable ${ }^{42}$. Por otro lado, que no sean obligatorias desde el punto de vista legal no significa que tengan un carácter meramente voluntario, pues, aunque no tengan consecuencias jurídicas, pueden tener otro de tipo de impacto negativo para las empresas multinacionales que no las cumplan. En consecuencia, en la medida en que la reputación de la empresa puede verse afectada por el incumplimiento de las Líneas Directrices y, en última instancia, esto puede afectar a la generación de ganancias económicas, la voluntariedad de dicho instrumento puede considerarse relativa ${ }^{43}$. En esta línea, una parte de la doctrina ha llegado a afirmar que las Líneas Directrices de la OCDE para empresas multinacionales son el instrumento internacional que, pese a su aparente debilidad desde el punto de vista de la exigibilidad jurídica inmediata, se ha revelado como uno de los que más incidencia tiene en la práctica $^{44}$.

Las valoraciones en torno a la eficacia de las Líneas Directrices van a depender del punto de vista que se adopte. Mientras que, por un lado, la ausencia de coercibilidad y obligatoriedad, característica básica de las normas jurídicas, puede verse como una desventaja, por otro lado, es necesario atender al objetivo que se fijaron las Directrices cuando se adoptaron en 1976, y que permanece intacto en la actualidad. Las Directrices no pretenden ser un "código legal internacional que rija el comportamiento externo de las empresas multinacionales", sino, tal y como se indica en el capítulo de "Conceptos y principios", un conjunto de recomendaciones destinadas a crear un ambiente favorable en el ámbito de la inversión internacional ${ }^{45}$. En consecuencia, su eficacia no depende tanto de si son vinculantes o no, sino de si realmente influyen en la conducta de las empresas multinacionales. En este sentido, podrán considerarse eficaces si logran que las empresas las tengan en cuenta, aunque no creen obligaciones jurídicas.

\footnotetext{
${ }^{40}$ CANTÚ RIVERA, Humberto, op. cit., p. 645.

${ }^{41}$ GIL Y GIL, José Luis, "Globalización y universalidad del derecho: la lex mercatoria y el derecho internacional del trabajo en el mercado global", op. cit., pp. 23, 24 y 33, y "La dimensión social de la globalización en los instrumentos de la OIT", op. cit., pp. 29, 30 y 35.

${ }^{42}$ BLANPAIN, Roger, op. cit., p. 348.

${ }^{43}$ CANTÚ RIVERA, Humberto, op. cit., p. 637.

${ }^{44}$ JIMÉNEZ SÁNCHEZ, José Joaquín, op. cit., p. 18.

45 JIMÉNEZ SÁNCHEZ, José Joaquín, op. cit., p. 85.
} 


\section{Los capítulos sobre derechos humanos y sobre empleo y relaciones laborales}

En cuanto al contenido de las Líneas Directrices de la OCDE para empresas multinacionales, aunque se refieren a una variedad de materias, en el presente artículo nos centraremos en los capítulos relativos a los derechos humanos y al empleo y relaciones laborales.

Tal y como ya se ha apuntado, el capítulo IV de la Parte I de las Líneas Directrices sobre derechos humanos se introdujo en la revisión del año 2011 ${ }^{46}$. Este capítulo toma como punto de referencia los Principios Rectores de la ONU sobre empresas y derechos humanos y, de hecho, sus disposiciones en la materia son muy similares, o casi idénticas, a las que se recogen en el instrumento de la ONU.

En primer lugar, las Directrices recuerdan que los Estados tienen el deber de proteger los derechos humanos. A continuación, y en el marco de los derechos humanos internacionalmente reconocidos y de los compromisos internacionales en la materia suscritos por los países en los que las empresas ejercen su actividad, así como en el marco de las leyes y regulaciones nacionales pertinentes ${ }^{47}$, las Directrices enuncian una serie de deberes para las empresas multinacionales. La primera es una obligación de carácter general, pues se indica que deberán respetar los derechos humanos, es decir, tienen que velar por no vulnerar los derechos de los demás y también han de hacer frente a los impactos negativos sobre los derechos humanos en los que se vean implicadas. En esta misma línea, a continuación, las Directrices enuncian una serie de obligaciones de carácter preventivo dirigidas a evitar o a atenuar el impacto negativo en los derechos. Ahora bien, también les imponen, en cierta medida, una obligación "de hacer", pues señalan que tienen que hacer frente y resolver los impactos negativos que se generen en los derechos humanos. Además, la empresa multinacionales deberá elaborar una política que formule su compromiso con el respeto de los derechos humanos.

La debida diligencia es otra de las obligaciones de las empresas multinacionales a las que se refieren las Directrices, y también cabría incluirla entre las medidas de carácter preventivo $^{48}$. Este concepto también existe en los Principios Rectores de la ONU sobre

\footnotetext{
${ }^{46}$ La progresiva incorporación de los derechos humanos a las Directrices de la OCDE se correspondió con la reaparición del debate en el seno de la ONU, en particular desde que John Ruggie fue nombrado Representante Especial del Secretario General de la ONU para los Derechos Humanos y las Empresas. De hecho, en su informe de 2006 ya destacaba el potencial del sistema de PNC previstos en las Líneas Directrices para "contribuir a resolver los problemas de las empresas en los derechos humanos porque no sólo cubre aspectos en el plano nacional sino también en los países receptores". Sin embargo, también ponía de manifiesto que los resultados de los PNC eran muy desiguales, sobre todo en relación con los derechos humanos. Dicho informe puede consultarse en el siguiente link: https://www.businesshumanrights.org/sites/default/files/media/bhr/files/Ruggie-HRC-2006-Es.pdf

${ }^{47}$ Se refieren a la Carta Internacional de Derechos Humanos, que comprende la Declaración Universal de Derechos Humanos y los principales instrumentos a través de los que fue codificada: el Pacto Internacional de Derechos Civiles y Políticos y el Pacto Internacional de Derechos Económicos, Sociales y Culturales, así como los principios sobre derechos fundamentales expuestos en la Declaración de la OIT de 1998 relativa a los principios y derechos fundamentales del trabajo.

${ }^{48}$ Sobre el concepto de debida diligencia en las Líneas Directrices de la OCDE y en los Principios Rectores de la ONU, véase: BUENO, Nicolas, "Multinational enterprises and labour rights: concepts and
} 
empresas y derechos humanos. Las Directrices señalan que las empresas multinacionales deberán "ejercer la debida diligencia en materia de derechos humanos en función de su tamaño, de la naturaleza y el contexto de sus actividades y de la gravedad de los riesgos de impactos negativos sobre dichos derechos". Los comentarios de las Líneas Directrices sobre este capítulo nos aclaran que dicho proceso ha de llevarse a cabo siguiendo unas fases. En primer lugar, la empresa tiene que evaluar los impactos reales o potenciales sobre los derechos humanos; en segundo lugar, integrará los resultados de dicha evaluación y pondrá en práctica las acciones correspondientes; a continuación, hará un seguimiento de las respuestas y, por último, comunicará las medidas tomadas para hacer frente a los impactos. La debida diligencia contribuye a que las empresas anticipen y prevengan o mitiguen los impactos negativos en los derechos humanos. Su objetivo es, ante todo, evitar causar o contribuir a impactos negativos sobre las personas, el medio ambiente y la sociedad. Cuando no se puede evitar la participación en impactos negativos, la debida diligencia debe permitir a las empresas mitigarlos, prevenir su recurrencia y, cuando corresponda, repararlos.

En el año 2018, la OCDE publicó una Guía de debida diligencia para una conducta empresarial responsable ${ }^{49}$, en la que señala que dicho concepto no se limita al ámbito de los derechos humanos, sino que también aborda los impactos negativos reales o potenciales (riesgos) relacionados con otros de los temas sobre los que tratan las Líneas Directrices, como el empleo y las relaciones laborales, el medio ambiente, el cohecho y la corrupción, la divulgación de información y los intereses de los consumidores.

Por último, las Directrices señalan que las empresas deberán "establecer mecanismos legítimos o cooperar mediante estos mecanismos para poner remedio a los impactos negativos sobre los derechos humanos cuando se descubra que han causado dichos impactos o que han contribuido a generarlos".

Algunos autores han entendido que el capítulo sobre derechos humanos de las Líneas Directrices podría considerarse uno de los puntos de este instrumento que va más allá del concepto de responsabilidad social. En este sentido, al estar fundamentado en el respeto de los derechos humanos internacionalmente reconocidos, podría circunscribirse, al menos de manera parcial, en una perspectiva parcialmente jurídica ${ }^{50}$. Sin embargo, esta interpretación no puede compartirse, puesto que, aunque en el capítulo sobre derechos humanos se utiliza la expresión "las empresas deberán", en realidad, como ya hemos visto, las Directrices tienen el carácter de recomendaciones no vinculantes. En consecuencia, las empresas estarán obligadas a respetar los derechos humanos, a poner en práctica la debida diligencia y a articular mecanismos para remediar los daños causados en los derechos humanos en la medida en que así lo establezcan las normas nacionales o internacionales sobre la cuestión, pero no porque lo señalen las Directrices

implementation", en Bellace, J.R., Blank, S., Haar, B.P.ter (directores), Research handbook on labour, business and human rights law, Edward Elgar, 2019.

${ }^{49}$ https://mneguidelines.oecd.org/Guia-de-la-OCDE-de-debida-diligencia-para-una-conducta-empresarialresponsable.pdf

${ }^{50}$ CANTÚ RIVERA, Humberto, op. cit., p. 638. 
de la OCDE. El régimen de responsabilidad para las empresas multinacionales que crean las Directrices no ha cambiado tras la inclusión del capítulo sobre derechos humanos en la revisión de $2011 \mathrm{y}$, por lo tanto, seguimos moviéndonos en el terreno de la responsabilidad social empresarial o corporativa.

Las Líneas Directrices también dedican un capítulo, en concreto el V, al empleo y las relaciones laborales ${ }^{51}$. En primer lugar, se refieren al "marco de las disposiciones legales y regulatorias aplicables y de las prácticas vigentes en materia de empleo y relaciones laborales, así como de las normas laborales internacionales que resulten de aplicación". En los comentarios de las Líneas Directrices, se aclara que esta introducción hace referencia a las leyes y regulaciones, tanto nacionales como internacionales, que resulten de aplicación a las empresas multinacionales que operan en un determinado territorio.

Las Líneas Directrices de la OCDE no incorporan nuevos deberes para las empresas multinacionales en el ámbito del empleo y de las relaciones laborales, sino que recogen recomendaciones destinadas a promover la observancia de las normas internacionales del trabajo elaboradas por la OIT y de las respectivas normas nacionales. Tal y como se establece en los comentarios de las Líneas Directrices, la OIT es el órgano competente encargado de establecer las normas laborales internacionales y de promover los derechos fundamentales en el trabajo reconocidos en la Declaración de la OIT de 1998 relativa a los principios y derechos fundamentales en el trabajo. Por lo tanto, las Directrices de la OCDE, como instrumento no vinculante, tienen la función de impulsar el cumplimiento de estas normas y principios por parte de las empresas multinacionales.

El capítulo sobre empleo y relaciones laborales consta de un total de 8 párrafos, que se dividen a su vez en múltiples subapartados, que hacen referencia a una serie de pautas de conducta que las empresas multinacionales "deberán" respetar. Por su parte, la Declaración de la OIT sobre empresas multinacionales utilizaba la expresión "deberían”. Con todo, como ya se indicó en relación con el capítulo sobre derechos humanos, la utilización de la expresión "deberán” no significa que las Líneas Directrices impongan verdaderas obligaciones para las empresas multinacionales.

Las disposiciones en materia de empleo y relaciones laborales pueden dividirse en distintos bloques que, sin ánimo de exhaustividad, se expondrán a continuación. En el primer bloque, las Líneas Directrices se refieren al deber de respetar una serie de principios y derechos que se corresponden con los enunciados en la Declaración de la OIT de 1998 (la libertad de asociación y el derecho a la negociación colectiva, la abolición efectiva del trabajo infantil, la eliminación de todas las formas de trabajo forzoso $\mathrm{u}$ obligatorio y la no discriminación de empleo ni de profesión). Estos principios y derechos han sido desarrollados como derechos y obligaciones específicos en los Convenios de la OIT reconocidos como fundamentales. En consecuencia, una vez más, las empresas multinacionales no están obligadas a respetarlos porque dicho deber se configure en las Líneas Directrices de la OCDE, sino porque lo impone la Declaración de la OIT.

\footnotetext{
${ }^{51}$ Para un análisis detallado de este capítulo de las Líneas Directrices, véase DAUGAREILH, Isabelle, "La dimension sociale...", op. cit., p. 571 y ss.
} 
El segundo bloque versa sobre las consultas y la cooperación entre las empresas y los trabajadores y sus representantes respecto a cuestiones de interés común. El tercero se refiere al principio de igualdad de trato. En concreto, las Líneas Directrices señalan que las empresas multinacionales deberán respetar unas normas de empleo y de relaciones laborales que no sean menos favorables que las que existen en empresas similares del país en el que se desempeña la actividad, incluyendo la remuneración y la jornada. El cuarto bloque trata el tema de la seguridad y salud en el trabajo, aunque su contenido es más breve que el de la Declaración tripartita de la OIT El siguiente párrafo recoge una recomendación que no está estrictamente relacionada con las normas de empleo y relaciones laborales, pues señala que las empresas fomentarán, en la medida de lo posible, la contratación y formación del personal local. El último de los bloques trata sobre los preavisos en caso de despido colectivo.

Tal y como puede apreciarse, el contenido de las Líneas Directrices en relación con los derechos humanos y con el empleo y las relaciones laborales no resulta novedoso, pues está inspirado en otros instrumentos internacionales -los Principios Rectores de la ONU y la Declaración de la OIT, respectivamente-. Las Líneas Directrices se limitan a promover el respeto por parte de las empresas multinacionales de los principios recogidos en dichos instrumentos.

\section{La puesta en práctica de las Líneas Directrices: los Puntos Nacionales de Contacto y el Comité de Inversión}

Además de las recomendaciones para una conducta empresarial responsable en el contexto global, que recogen en la primera parte del documento, en la segunda, las Líneas Directrices hacen referencia a una serie de procedimientos para su desarrollo.

La puesta en práctica de las Líneas Directrices de la OCDE está respaldada por un órgano específico que los gobiernos adherentes habrán de crear a tal efecto -los Puntos Nacionales de Contacto (PNC)- y por una serie de mecanismos ad hoc, pero también por el Comité de Inversión de la OCDE. Ahora bien, se trata de órganos y mecanismos para favorecer la eficacia de las Directrices y no para controlar su cumplimiento por parte de las empresas multinacionales. Los PNC no son tribunales y no juzgan ni fiscalizan si las empresas multinacionales han cumplido o no con las Líneas Directrices. En consecuencia, ni los PNC ni el Comité de Inversión podrán imponer verdaderas sanciones a las empresas que hayan incumplido las recomendaciones que les han hecho. Con todo, los PNC juegan un papel muy importante desde el punto de vista de la responsabilidad -social corporativade las empresas multinacionales por incumplimiento de las Directrices. Por otro lado, aunque, como se establece en el comentario sobre la Guía de procedimiento para los PNC, son las empresas multinacionales quienes deben respetar las Directrices en su actividad diaria, los gobiernos pueden contribuir a mejorar la eficacia de los procedimientos de desarrollo, por lo que los PNC desempeñan una función muy relevante a la hora de dotar de mayor eficacia a las Directrices. 
Los PNC asumieron más funciones desde la revisión de las Líneas Directrices del año 2000, pero, en realidad, ya existían desde mucho antes. En concreto, surgieron en 1979 como un mero punto de contacto, y no fue hasta 1984 cuando se estableció que cada país adherente a las Directrices debía crear un $\mathrm{PNC}^{52}$.

La Decisión del Consejo sobre las Líneas Directrices de la OCDE para empresas multinacionales establece las obligaciones de los países adherentes en relación con los PNC. En primer lugar, cada gobierno ha de crear un PNC e informar a las partes interesadas de la existencia de este tipo de mecanismos relacionados con las Líneas Directrices. En la actualidad, existen 49 PNC, pues todos los gobiernos adherentes a las Directrices han creado el suyo. En el caso de España, el PNC se configura como un órgano colegiado interministerial, adscrito al Ministerio de Economía y Competitividad, a través de la Secretaría de Estado de Comercio ${ }^{53}$.

Los gobiernos tienen flexibilidad a la hora de organizar sus PNC, siempre que se garantice la equivalencia funcional entre los distintos países. Esta fue una cuestión muy controvertida en los debates sobre la actualización de las Directrices de 2011. Sin embargo, no se logró llegar a un acuerdo para la unificación de los procedimientos ante los PNC, pues las cuestiones procedimentales son un tema que está muy vinculado con la soberanía de cada estado. Esta disparidad de procedimientos supone un problema, pues, en un mundo globalizado, la existencia de diferentes procedimientos en los distintos PNC puede provocar resultados incoherentes ${ }^{54}$. Para garantizar una mínima armonización y fomentar el cumplimiento de la equivalencia funcional, las Líneas Directrices enuncian una serie de criterios - visibilidad, accesibilidad, transparencia y responsabilidadconforme a los cuales tendrán que operar los PNC. Con todo, su aplicación en la práctica no es una tarea sencilla.

En segundo lugar, una vez creados, los Estados tienen que poner a disposición de los PNC los recursos humanos y financieros que necesiten para desarrollar su actividad, permitirles colaborar con los PNC de otros países y reunirse de manera regular, así como también presentar informes al Comité de Inversión. Cabe señalar que existe un fuerte compromiso entre los distintos países miembros de la OCDE, para garantizar que los PNC sean un mecanismo efectivo de reclamación extrajudicial, y para que sigan mejorando ${ }^{55}$. En esta

\footnotetext{
52 VAN'T FOORT, Sander, op. cit., p. 201.

${ }^{53}$ El PNC español se estableció en 2001, pero no fue hasta 2014, con la Orden PRE/2167/2014, de 11 de noviembre, cuando se definió su composición y funcionamiento. Con todo, hasta entonces, las funciones del PNC ya habían sido asumidas por el Ministerio con competencia en materia de comercio. En el siguiente link, puede consultarse la página web del PNC español: https://www.comercio.gob.es/es-ES/inversionesexteriores/punto-nacional-contacto-lineas-directrices/Paginas/El_PNC.aspx

${ }^{54}$ Véase WEBER, Rolf H., Development of coherent procedural rules for OECDE Guidelines' mediation, Draft background paper, Roundtable on Forty years of the OECD Guidelines for Multinational Enterprises, París, 19 diciembre 2016, p. 2. Disponible en: http://mneguidelines.oecd.org/40-Years-OECD-Guidelines2016-Background-Paper1.pdf

55 En la Declaración posterior a la cumbre celebrada en junio de 2015, los miembros del GP se comprometieron a reforzar los mecanismos para ofrecer remedio a las víctimas, incluidos los PNC previstos en las Líneas Directrices para empresas multinacionales de la OCDE. En el mismo sentido se pronunciaron los líderes del G20 en su Declaración de 2017, en la que indicaron que apoyaban los mecanismos de queja no judiciales como los PNC.
} 
línea, en los últimos años, la OCDE ha publicado dos planes de acción para fortalecer los PNC, el primero para el periodo 2016-2018, y el último para 2019-2021 ${ }^{56}$.

Las funciones de los PNC pueden clasificarse en tres grupos: información y promoción, implementación de instancias específicas y elaboración de informes. En el ámbito de sus funciones de información y promoción, los PNC tendrán que realizar una serie de actividades, entre las que se incluyen darlas a conocer, generar conciencia sobre las Líneas Directrices a través de la cooperación con distintos actores, e informar al sector empresarial, a las organizaciones de trabajadores, $\mathrm{u}$ otras organizaciones no gubernamentales y otras partes interesadas acerca de la disponibilidad de estos mecanismos. En segundo lugar, los PNC responderán a las consultas que les presenten otros PNC, pero también el sector empresarial, las organizaciones de trabajadores, otras organizaciones no gubernamentales y el público, e incluso los gobiernos de países no adherentes a las Directrices.

La "implementación de instancias específicas" o tratamiento de casos específicos o quejas, siguiendo la terminología que utiliza el PNC español ${ }^{57}$, existe desde la revisión de las Directrices del año 2000 y es, sin duda, la función más importante de los PNC ${ }^{58}$. Las Directrices atribuyen a los PNC el mandato de actuar como un foro de discusión (forum for discussion). Los PNC contribuyen al estudio y solución de los problemas que surjan en relación con la aplicación de las Líneas Directrices en casos específicos, es decir, el PNC "contribuye a resolver", pero no resuelve las quejas sobre el presunto incumplimiento de las Directrices por parte de una empresa multinacional. Las Líneas Directrices de la OCDE son el único instrumento sobre la responsabilidad social empresarial en el ámbito internacional, respaldado por los gobiernos, que cuenta con un mecanismo específico de queja no judicial ${ }^{59}$.

El PNC ofrece asistencia a las empresas multinacionales, a las organizaciones de trabajadores o a otras partes interesadas. Cualquier persona puede presentar una queja ante los PNC, siempre y cuando demuestre que tiene un interés o preocupación legítima

\footnotetext{
56 OCDE, Action Plan to Strengthen National Contact Points for Responsible Business Conduct 2019 2021. Disponible en:

https://mneguidelines.oecd.org/Action-Plan-to-Strengthen-National-Contact-Points-for-ResponsibleBusiness-Conduct-2019-2021.pdf

${ }^{57}$ La versión en español de las Líneas Directrices aclara que "instancia específica” es la denominación que se utiliza en la mayoría de los países adherentes de habla hispana y por OECD Watch. Se corresponde a la traducción literal de la denominación oficial en inglés specific instance. Sin embargo, el PNC español se decanta por la expresión "casos específicos": Ministerio de Economía y Competitividad, Guía de procedimiento para la resolución de casos específicos. Punto Nacional de Contacto de las Líneas Directrices de la OCDE para empresas multinacionales, 2015. Disponible en: http://www.comercio.mineco.gob.es/esES/inversiones-exteriores/punto-nacional-contacto-lineas-directrices/PDF/Guia-Procedimiento-PNC-1511-20.pdf

En el presente artículo se utilizarán ambas de manera indiferenciada.

${ }^{58}$ Para un análisis en detalle, véase OLIVER, María Fabiana, GRUNAUER, Roque A., SERRANI, Esteban, Una herramienta de la RSE: Líneas Directrices de la OCDE, Buenos Aires, Fundación Ambiente y Recursos Naturales, 2006.

${ }^{59}$ OCDE, Implementing the OECD Guidelines for Multinational Enterprises: The National Contact Points from 2000 to 2015, 2016, p. 29. Disponible en: https://mneguidelines.oecd.org/OECD-report-15-yearsNational-Contact-Points.pdf
} 
en la cuestión. Aunque normalmente los casos específicos se presentan ante el PNC del país en el que se desarrolla la actividad empresarial cuestionada, los PNC también pueden tratar asuntos sobre empresas multinacionales que tengan su sede en ellos, aunque operen en otro país.

La Guía de procedimiento que aparece en las Líneas Directrices, introducida en la revisión de 2011, ofrece una serie de pautas a los PNC y al Comité de inversión sobre cómo gestionar los casos específicos. Los PNC tienen que actuar, en todo momento, de manera imparcial, previsible, equitativa y compatible con los principios y normas establecidos en las Directrices.

El tratamiento de los casos específicos se divide en tres fases. En primer lugar, la Guía de procedimiento de las Líneas Directrices establece que, una vez que recibe un caso, el PNC tendrá que llevar a cabo una evaluación inicial, para determinar si las cuestiones planteadas merecen un examen más detallado ${ }^{60}$. Una vez realizada esta primera aproximación al caso, el PNC dará una respuesta a las partes afectadas. Si el PNC estima que la cuestión no merece mayor consideración, emitirá un comunicado en el que tendrá que indicar los motivos en los que haya basado su decisión. Esta decisión no se puede apelar, por lo que se produce un "enjuiciamiento en vista única", aspecto que ha merecido importantes críticas por parte de la doctrina ${ }^{61}$. Por el contrario, si considera que puede contribuir a la resolución de la controversia, ofrecerá su asistencia a las partes implicadas.

En esta segunda fase, el PNC procederá a tramitar el caso que ha aceptado. El PNC analizará el asunto con mayor profundidad y brindará a las partes sus "buenos oficios", con el objetivo de contribuir de manera informal a la resolución de las cuestiones suscitadas. Para llevar a cabo su cometido, el PNC puede solicitar asesoramiento a las entidades pertinentes o a los representantes del sector empresarial o de las organizaciones de trabajadores. Asimismo, también tiene la posibilidad de requerir el apoyo de otros PNC. Como parte del ofrecimiento de buenos oficios, y cuando sea pertinente en función de las cuestiones que hayan surgido, los PNC ofrecerán o facilitarán el acceso a procedimientos consensuados y no contenciosos, como la conciliación o mediación. La utilización de estos métodos extrajudiciales de resolución de conflictos puede ser mucho más rápida y barata que los procesos judiciales o el arbitraje, y permiten a las partes involucrarse en el proceso para buscar un acuerdo ${ }^{62}$. Ahora bien, los PNC no pueden

\footnotetext{
${ }^{60} \mathrm{El}$ comentario sobre la Guía de procedimiento señala que, para llevar a cabo esta tarea, el PNC deberá comprobar si la parte que presentó la instancia específica actúo de buena fe y si la cuestión guarda relación con las Directrices. Además, el PNC tendrá en cuenta los siguientes criterios: la identidad de la parte afectada y su interés en la instancia; si la cuestión es significativa y está justificada; si pareciera existir una conexión entre las actividades de la empresa y la cuestión suscitada en la instancia específica; la pertinencia de la legislación y de los procedimientos aplicables, incluyendo las resoluciones judiciales; de qué manera cuestiones similares han sido, o están siendo, tratadas en otros procesos locales o internacionales y si la consideración de la instancia específica contribuirá al objeto y la eficacia de las Directrices.

${ }^{61}$ JIMÉNEZ SÁNCHEZ, José Joaquín, op. cit., p. 90.

${ }^{62}$ La propia OCDE lo ha identificado como una de las mayores ventajas de las Líneas Directrices en el informe: OCDE, Implementing the OECD Guidelines for Multinational Enterprises: The National Contact Points from 2000 to 2015, 2016, p. 30.
} 
imponer su uso, sino que serán las partes involucradas quienes decidan si quieren acudir o no a dichos procedimientos.

Una vez realizada esta asistencia, el caso puede concluir con o sin acuerdo entre las partes. Si las partes llegan a un acuerdo, el PNC emitirá un comunicado en el que deberá describir las cuestiones que hubiesen surgido, las acciones que llevó a cabo para auxiliar a las partes y la fecha en que se produjo dicho acuerdo. La publicación del contenido del citado acuerdo quedará sujeto al consentimiento de las partes. Por otro lado, el PNC dictará un informe cuando las partes involucradas no lleguen a un acuerdo y también si una de ellas se hubiese negado a participar en los procedimientos. Dicho informe incluirá los motivos por los cuales el PNC había estimado que la cuestión merecía un examen más detallado, el detalle las acciones que el PNC puso en práctica para asistir a las partes y las razones por las que el acuerdo entre las partes no fue factible. Además, el PNC deberá formular una serie de recomendaciones apropiadas para la puesta en práctica de las Directrices en el caso específico.

En ambos casos, el tratamiento de los casos específicos por parte de los PNC concluirá con la publicación de los resultados, pero siempre teniendo en cuenta la necesidad de proteger la información sensible. La publicación de los comunicados e informes es, de hecho, la única consecuencia del procedimiento de resolución de casos específicos ante los PNC. No se establece ninguna otra implicación para las empresas multinacionales que se nieguen a participar en los procedimientos, ni tampoco para aquellas que no sigan las recomendaciones realizadas por los PNC. El único impacto negativo para las empresas multinacionales a las que se les imputa el incumplimiento de las Líneas Directrices es la repercusión mediática y social. La difusión de la queja y de su contenido puede generar mala publicidad a la empresa y repercutir en su fama y reputación.

Entre el año 2000 y el 2018 los PNC han tratado más de $450 \operatorname{casos}^{63}$. La mayoría de las veces fueron los sindicatos o las ONGs quienes plantearon dichas instancias específicas. En el periodo 2001-2011, la mayoría de los casos, en concreto el 70\%, tenían que ver con el capítulo sobre empleo y relaciones laborales. Sin embargo, desde que en 2011 se introdujo el capítulo sobre derechos humanos, la mayoría de las instancias específicas, exactamente el 57\%, han versado sobre este ${ }^{64}$. En el periodo 2011-2018, aproximadamente la mitad de los casos que el PNC admitió a trámite concluyeron con algún tipo de acuerdo entre las partes.

La $O E C D$ Watch, red mundial de organizaciones de la sociedad civil que promueve la responsabilidad empresarial y el acceso a la reparación para las víctimas de abusos cometidos por las empresas, publicó un informe en 2015, en el que analizaba los casos que habían llegado a los PNC en sus primeros 15 años de existencia, y su contribución a la mejora del acceso a un remedio para las víctimas de conductas abusivas de las empresas

63 Véase la base de datos de la OCDE sobre instancias específicas en el siguiente link: http://mneguidelines.oecd.org/database/

${ }^{64}$ Véase el análisis elaborado por la OCDE sobre los casos que se presentaron ante los PNC, disponible en el siguiente link: http://mneguidelines.oecd.org/Flyer-OECD-National-Contact-Points.pdf 
multinacionales ${ }^{65}$. En dicho informe, la citada organización identificó una serie de problemas en la actuación de los PNC relacionados con los criterios fundamentales para la equivalencia funcional en las actividades de los PNC -visibilidad, accesibilidad, transparencia y responsabilidad ${ }^{66}$ - y con los principios generales aplicables a instancias específicas -imparcialidad, previsibilidad, equidad y compatibilidad con las Directrices-. Por su parte, la propia OCDE ha elaborado a lo largo de los años diversos informes en los que ha reconocido que los mecanismos de los PNC presentaban algunas debilidades. Entre ellas, destaca la ausencia de uniformidad entre los procedimientos de los distintos $\mathrm{PNC}^{67}$.

En su informe, y en relación con la compatibilidad con las Directrices ${ }^{68}$, la OCDE Watch llegó a la conclusión de que un elevado número de PNC no actúan de manera conforme con las Directrices, puesto que, en el informe que emiten cuando no ha habido acuerdo entre las partes, no se pronuncian sobre si ha habido o no incumplimiento por parte de las empresas multinacionales. La OECD Watch continúa señalando que, en sus informes finales, los PNC evitan entrar a analizar el fondo del asunto, aun cuando cuentan con las pruebas suficientes para hacerlo. Ahora bien, hay que tener en cuenta que ni las Líneas Directrices ni la Guía de procedimiento prevén, en ningún momento, que los PNC tengan que elaborar un informe en el se pronuncien sobre si ha habido o no incumplimiento de las Líneas Directrices. Tampoco prevén la imposición de sanciones ni mecanismos de ejecución por parte de los PNC. La labor de los PNC en relación con los casos específicos consiste, únicamente, en promover o facilitar la resolución de la controversia entre las partes. En este caso, por lo tanto, estaríamos más bien ante un problema de mandato y no de compatibilidad con las Directrices, puesto que el PNC estará actuando en línea aquellas, aunque no se pronuncie sobre estos particulares ${ }^{69}$. En consecuencia, no se puede pedir a los PNC que impongan sanciones a las empresas multinacionales en el marco de las instancias específicas, cuando las Líneas Directrices no lo prevén. De hecho, si el PNC de un determinado país lo hace será porque está siguiendo unos criterios de actuación internos que ha fijado su propio gobierno, y no con base en las Líneas Directrices de la OCDE para empresas multinacionales ${ }^{70}$. Con todo, de acuerdo con el informe anual sobre

\footnotetext{
${ }^{65} \mathrm{OECD}$ Watch, Remedy remains rare. An analysis of 15 years of NCP cases and their contribution to improve access to remedy for victims of corporate misconduct, junio 2015. Disponible en: https://www.oecdwatch.org/2015/06/01/remedy-remains-rare/

${ }^{66}$ La $O E C D$ Watch llegó a la conclusión de que el aspecto de la accesibilidad era el más preocupante. Entre los aspectos que cita, destaca la excesiva onerosidad que el acceso a los PNC implica para las víctimas, tanto en términos económicos como de represalias. Además, el informe señala que, por lo general, los PNC requieren que la parte que presenta la instancia específica aporte un volumen excesivo de pruebas en la fase de la evaluación inicial. Otro de los problemas sería la utilización de criterios diferentes a los mencionados en el comentario sobre la Guía de Procedimiento en el momento de la evaluación inicial. Por último, la $O E C D$ Watch ha constatado que una gran parte de los PNC rechazan aceptar casos que versen sobre el impacto potencial de las acciones de la empresa multinacional.

${ }^{67} \mathrm{OCDE}$, Implementing the OECD Guidelines for Multinational Enterprises: The National Contact Points from 2000 to 2015,2016 , p. 30 y ss.

${ }^{68} \mathrm{La} O E C D$ Watch entiende que la contribución a la "resolución de las instancias específicas de manera compatible con los principios y normas establecidos en las Directrices" tiene que interpretarse de acuerdo con el objetivo último de los PNC, es decir, la promoción de la efectividad de las Líneas Directrices.

${ }^{69}$ WEBER, Rolf H., op. cit., p. 5.

${ }^{70}$ WEBER, Rolf H., op. cit., p. 5.
} 
las Líneas Directrices, casi la mitad de los informes que publicaron los PNC en el año 2018 se pronunciaban acerca de si la empresa multinacional implicada en la instancia específica había cumplido o no las Directrices ${ }^{71}$.

Para la doctrina, el hecho de que las Líneas Directrices no señalen que los PNC tienen que pronunciarse acerca del incumplimiento de las Líneas Directrices y no estén facultados para imponer sanciones a las empresas multinacionales constituye la mayor desventaja de las Directrices, pues entienden que reduce su impacto y su potencial a la hora de evitar que las empresas repitan los mismos compartimientos. El reproche que imponen, en consonancia con su carácter de soft law, es más moral que jurídico. En consecuencia, haciéndose eco de las impresiones preponderantes entre los sindicatos y las ONGs, algún autor ha entendido que la debilidad de sus mecanismos es el verdadero talón de Aquiles de las Directrices ${ }^{72}$.

Por otro lado, algunos expertos en la materia han entendido que, si en una futura revisión de las Directrices se busca potenciar la efectividad de su contenido y de sus procedimientos, uno de los principales temas a tratar sería, precisamente, el de la participación de las empresas en los procedimientos de instancias específicas y, en particular, la imposición de una serie de consecuencias para aquellas que rehúsen colaborar con las instancias o que ignoren las recomendaciones del PNC correspondiente $^{73}$. En el mismo sentido se pronuncia OECD Watch. La citada red recomienda a los gobiernos adherentes a las Directrices que realicen varias reformas en los PNC, entre otros, que les otorguen la capacidad de aplicar consecuencias a las empresas multinacionales que se nieguen a colaborar con ellos o que no pongan en práctica sus recomendaciones, así como a las que no cumplan con las Directrices. Según OECD Watch, estas consecuencias podrían consistir en la exclusión de los privilegios relacionados con la promoción comercial, de los contratos públicos, de los seguros de crédito a la exportación y de las misiones de inversores ${ }^{74}$. Ahora bien, se plantean dudas acerca de cómo habría que articular dichas consecuencias, puesto que, en la medida en que las empresas multinacionales no están obligadas a respetar las Líneas Directrices, parece difícil imaginar cómo podrían llegar a estar vinculadas por sus procedimientos de desarrollo. En consecuencia, se entiende que, para potenciar la obligatoriedad de participar en los procedimientos sobre instancias específicas, primero habría que modificar el valor jurídico de las propias Líneas Directrices. En este sentido, otra posibilidad que ha identificado la doctrina consistiría en que los Estados adherentes

\footnotetext{
${ }^{71}$ OCDE, Annual Report on the OECD Guidelines for Multinational Enterprises 2018, 2019, p. 25. En el informe se recogen dos ejemplos de los PNC holandés y noruego.

72 JIMÉNEZ SÁNCHEZ, José Joaquín, op. cit., p. 89 y ss.

${ }^{73}$ RUGGIE, John Gerard, Just business: multinational corporations and human rights, Nueva York, W. W. Norton \& Company, 2013, p. 176.

${ }^{74}$ OCDE Watch, The State of Remedy under the OECD Guidelines. Understanding NCP cases concluded in 2018 through the lens of remedy, OECD Watch Briefing Paper, junio 2019, p. 14. Disponible en: https://www.oecdwatch.org/2019/06/12/the-state-of-remedy-under-the-oecd-guidelines-understandingncp-cases-concluded-in-2018-through-the-lens-of-remedy/
} 
determinasen en su legislación interna la obligación de las empresas multinacionales de respetar las Líneas Directrices de la OCDE y de comparecer ante los $\mathrm{PCN}^{75}$.

Por otro lado, aunque las Directrices carecen de fuerza jurídica obligatoria para las empresas multinacionales, la doctrina ha entendido que los PNC crean una especie "jurisprudencia" acerca de cómo han de interpretarse y aplicarse, que podría ser muy útil para la búsqueda de elementos orientados a la responsabilidad de las empresas multinacionales. En consecuencia, las Líneas Directrices de la OCDE no pueden reducirse a la categoría de una simple declaración de intenciones ${ }^{76}$. En concreto, y en relación con el capítulo sobre derechos humanos, aunque también podría extenderse al resto de capítulos, algunos autores entienden que, cuando las partes en una instancia específica no logran llegar a un acuerdo y el PNC realiza recomendaciones para la correcta puesta en práctica de las Directrices, estaría creando el equivalente a una "jurisprudencia" sobre la cuestión, es decir, una interpretación oficial del contenido de las Líneas Directrices de la OCDE para empresas multinacionales ${ }^{77}$.

La OCDE no ha permanecido ajena a las críticas en torno al funcionamiento de los PNC y de sus mecanismos. De hecho, desde 2015, ha promovido las evaluaciones voluntarias entre pares de los PNC, a las que hacen referencia las Líneas Directrices, como una forma para mejorar su funcionamiento, pues permiten identificar los aspectos que necesitan mejorarse $^{78}$.

Para conocer cómo funcionan en la práctica los PNC, nos centraremos en el caso español. El PNC de España ha analizado un total de 7 casos específicos, 2 sobre el capítulo de empleo y relaciones laborales y otro sobre derechos humanos. Los cuatro primeros son anteriores a la publicación de la Guía de procedimiento, por lo que no disponen de informe final. Dos de ellos versaban sobre el capítulo de empleo y relaciones laborales de las Líneas Directrices ${ }^{79}$.

${ }^{75}$ CANTÚ RIVERA, Humberto, op. cit., p. 645.
${ }^{76}$ DAUGAREILH, Isabelle, "Responsabilidad social...”, op. cit., p. 86.
${ }^{77}$ RUGGIE, John Gerard, op. cit., p. 175.
${ }^{78}$ En la Reunión del Consejo Ministerial de la OCDE, los distintos ministros se comprometieron a continuar
con sus esfuerzos para reforzar la actuación de los PNC, incluidas las evaluaciones por pares voluntarias.
Posteriormente, en 2017, se pusieron como objetivo contar con una evaluación de cada PNC para el año 2023.

Las evaluaciones que se han hecho hasta el momento han permitido identificar una serie de retos a los que se enfrentan los PNC, entre ellos destacan las dificultades para cumplir con el plazo indicativo de duración del procedimiento al que se refiere el comentario de la Guía de procedimiento (12 meses), para conseguir que las partes se involucren en el procedimiento o para asegurar que ambas tengan el mismo poder de negociación, pero también la ausencia de medios materiales y humanos que aseguren el correcto funcionamiento del PNC. Véase: OCDE, Progress report on National Contact Points for responsible business conduct, 2019. Disponible en: https://www.oecd.org/daf/inv/mne/progress-report-on-ncps-forresponsible-business-conduct-2019.htm

${ }^{79}$ Caso E-00001: Sindicato - Institución financiera (Venezuela): en mayo de 2004, el PNC recibió una petición de un sindicato en relación con una posible vulneración de dicho capítulo por parte de una empresa española en Venezuela. El PNC solicitó más información al sindicato, pero no respondió a los intentos de comunicación realizados por el PNC, por lo que se decidió cerrar el caso.

Caso E-00002: Sindicato - empresa multinacional (Perú): en diciembre de 2004, el PNC recibió una petición por parte de un sindicato que alegaba que una empresa española situada en Perú había incumplido el 
En relación con el caso sobre derechos humanos ${ }^{80}$, en noviembre de 2013 el sindicato UNI Global Union se dirigió al PNC español poniendo de manifiesto varios sucesos en las filiales de Prosegur en Brasil, Colombia, Paraguay, Perú y Chile que, a su juicio, violaban las Líneas Directrices. En marzo de 2014, tras haber realizado la evaluación inicial, el PNC admitió el caso y ofreció sus buenos oficios. El PNC mantuvo varias reuniones con ambas partes, que tuvieron la naturaleza de una mediación informal. Sin embargo, la empresa Prosegur no aceptó la apertura de un procedimiento de mediación formal, pues condicionó su decisión a la suspensión, durante 6 meses, de la campaña pública de protestas en su contra que UNI Global Union estaba desarrollando. El sindicato no aceptó esta propuesta y ofreció, en su lugar, cesar dicha campaña durante un periodo de 3 meses. La empresa no aceptó este ofrecimiento, por lo que no hubo acuerdo entre las partes. Posteriormente, Prosegur solicitó el cierre del caso en diciembre de 2015, mientras que UNI Global Union mostró su desacuerdo al respecto. Con todo, el 31 de mayo de 2016, el PNC español adoptó la decisión de cierre por unanimidad del caso específico presentado por UNI Global Union, pues consideró que "el deseo de una de las partes de no continuar el proceso con el PNC impedía cualquier tipo de mediación".

En su informe final, el PNC recomendó a Prosegur que realizase una diligencia debida como complemento a los mecanismos que ya tenía establecidos en sus filiales latinoamericanas, para asegurarse de que los sucesos comunicados por UNI Global Union, sobre violaciones de derechos humanos en el entorno de la empresa, haya sido tenidos en cuenta por las filiales, y para que adoptasen medidas de remedio si fuesen necesarias. Por otro lado, el PNC consideró oportuno realizar un seguimiento de la aplicación de la recomendación por parte de la empresa y le propuso que lo informase en el plazo máximo un año desde la publicación de su informe final. Por último, el PNC español aclara que no entra a valorar aquellos aspectos sobre las relaciones laborales planteados por UNI Global Union que están pendientes de resolución en los tribunales de justicia. Tal y como puede apreciarse, en su informe, el PNC español ha incluido una recomendación a la empresa para que ponga en práctica las Directrices, en concreto los aspectos relativos a la debida diligencia. Ahora bien, se trata de una recomendación de carácter general, por lo que, en este caso, no estaríamos ante la función de creación de jurisprudencia de los PNC a la que se refiere la doctrina. Por otro lado, el PNC se ajusta a las Directrices y no se pronuncia de manera expresa sobre si ha habido o no un incumplimiento por parte de la empresa Prosegur.

El Comité de Inversión de la OCDE también realiza una serie de funciones para la puesta en práctica de las Líneas Directrices. En concreto, el Comité de Inversión es el órgano de la OCDE responsable de supervisar la aplicación de las Directrices, en particular por parte de los PNC. Ahora bien, la naturaleza no vinculante de las Directrices impide al Comité

\footnotetext{
capítulo sobre empleo y relaciones laborales, en particular en materia de salarios. El PNC se puso en contacto con ambas partes y como resultado se logró alcanzar un acuerdo.

${ }^{80}$ Informe Final del "caso específico" E-00005. UNI Global Union vs. Prosegur. Disponible en: https://www.comercio.gob.es/es-ES/inversiones-exteriores/punto-nacional-contacto-lineasdirectrices/PDF/180514-Informe-Final-Prosegur-UNI-GLOBAL-UNION.pdf
} 
actuar como un verdadero órgano judicial o cuasi-judicial. En consecuencia, no podrá cuestionar las declaraciones del PNC, salvo en aquellos casos en los que realice una interpretación de las Directrices. Lo que sí podrá hacer el Comité cuando analiza las actividades de los PNC es formular recomendaciones para mejorar su funcionamiento.

Entre sus múltiples funciones, destacan las siguientes. El Comité será el responsable de realizar cualquier aclaración necesaria respecto de las Directrices, en particular en relación con las instancias específicas. El Comité también considerará emitir una aclaración cuando un país adherente, un órgano consultivo u OECD Watch realice una solicitud debidamente motivada respecto de la correcta o incorrecta interpretación de las Directrices por parte de un PNC en un caso específico. Las partes tendrán la oportunidad de expresar sus opiniones ya sea en forma oral o por escrito. Esta sería una especie de segunda instancia en el procedimiento de instancias específicas, pues las partes pueden acudir a un órgano distinto y jerárquicamente superior al PNC. Ahora bien, la Decisión del Consejo sobre las Líneas Directrices de la OCDE para empresas multinacionales deja muy claro que, en el desempeño de esta labor de aclaración, el Comité se abstendrá de emitir conclusiones sobre la conducta de la empresa.

El Comité también juega un papel muy importante en relación con las evaluaciones voluntarias entre pares, pues el comentario de la Guía de procedimiento señala que las facilitará. Además, entre otras muchas funciones, el Comité también organiza intercambios de opinión sobre cuestiones relacionadas con las Directrices y presenta informes al Consejo de la OCDE sobre las Directrices.

\section{Conclusiones}

Las Líneas Directrices de la OCDE para empresas multinacionales son uno de los instrumentos interestatales más elaborados que existen en la actualidad, tanto desde el punto de vista de su contenido como del control de su aplicación ${ }^{81}$. Cuarenta y cuatro años después de su adopción, continúan siendo un instrumento muy relevante para promover la conducta responsable de las empresas multinacionales. De hecho, las Líneas Directrices se anticiparon a los cambios que se avecinaban en el ámbito de la inversión y de los negocios internacionales, por que lo que sus recomendaciones a las empresas multinacionales siguen de plena actualidad.

Con todo, es necesario reconocer que algunos de sus aspectos podrían mejorarse, sobre todo los relacionados sus procedimientos de puesta en práctica, para fortalecer el papel de las Líneas Directrices en el futuro ${ }^{82}$. En este sentido, resulta fundamental la armonización y la adecuación de los criterios que utilizan los PNC para resolver los casos específicos. La propia OCDE es consciente de las debilidades que presentan los PNC y

\footnotetext{
${ }^{81}$ DAUGAREILH, Isabelle, “Responsabilidad social...”, op. cit., p. 86.

${ }^{82}$ Véanse las propuestas al respecto de SANER, Raymond, "Investment trends and OECD Guidelines for multinational enterprises (The Guidelines) and the United Nations guiding principles (UNGPS)", en BONUCCI, Nicola y KESSEDJIAN, Catherine, 40 Years of the OCDE Guidelines for Multinational Enterprises, París, Editions A. Pedone, 2018, p. 161 y ss.
} 
está comprometida con su mejora. De hecho, desde 2015, está promoviendo la realización de evaluación voluntarias por parte de los PNC para identificar los ámbitos de mejora.

La falta de obligatoriedad de las Líneas Directrices ha sido otro de los aspectos que han suscitado mayores dudas. Es evidente que la existencia de un instrumento internacional de hard law que prevea la responsabilidad legal de las empresas multinacionales en caso de vulneración de los derechos humanos facilitaría la regulación de su actividad ${ }^{83}$. Sin embargo, no cabe infravalorar la importancia de los mecanismos de soft law, como las Líneas Directrices de la OCDE, pues también pueden contribuir a la conducta responsable de las empresas multinacionales ${ }^{84}$. De hecho, el reciente estudio sobre debida diligencia de la Comisión Europea ha puesto de manifiesto que las Líneas Directrices han influido en las percepciones de las empresas multinacionales en torno a dicho concepto ${ }^{85}$. Por lo tanto, las Líneas Directrices han demostrado ser un instrumento eficaz, en la medida en que influyen en la conducta de las empresas multinacionales, aunque no impongan responsabilidad jurídica.

Por otro lado, aunque las Directrices de la OCDE no sean vinculantes, pueden servir como base o guía para la elaboración de normas jurídicamente vinculantes en el futuro, tanto a nivel nacional como internacional. De hecho, como señala DAUGAREILH ${ }^{86}$, suele ocurrir que lo que "lo que es voluntario hoy se convierta en obligatorio mañana, que la obligación voluntaria de hoy sea el germen de la ley de mañana”. En este sentido, aunque sean un instrumento de soft law, las Líneas Directrices se convertirán en hard law si sus recomendaciones se incorporan en instrumentos jurídicos obligatorios ${ }^{87}$. Esto es lo que ocurrió, por ejemplo, en el caso de la Ley francesa sobre el deber de vigilancia de las casas matrices y empresas contratistas, también conocida como "ley sobre el deber de vigilancia de las empresas multinacionales" $"$, que se inspira de manera directa en las Líneas Directrices de la OCDE y en los Principios Rectores de la ONU ${ }^{89}$. En este sentido, las Líneas Directrices de la OCDE pueden servir como guía y contribuir al proceso de elaboración de una Directiva de la Unión Europea sobre debida diligencia obligatoria para

\footnotetext{
${ }^{83}$ En la actualidad, se está debatiendo en el seno de la ONU acerca de la elaboración de un tratado vinculante sobre empresas y derechos humanos. En concreto, el 17 de julio de 2019 el Consejo de Derechos Humanos de la ONU publicó el segundo borrador del Proyecto de Tratado vinculante sobre empresas y derechos humanos, que puede consultarse en el siguiente link: https://www.ohchr.org/Documents/HRBodies/HRCouncil/WGTransCorp/OEIGWG_RevisedDraft LBI.p $\underline{\mathrm{df}}$

${ }^{84}$ GIL Y GIL, José Luis, "Globalización y universalidad del derecho: la lex mercatoria y el derecho internacional del trabajo en el mercado global", op. cit., pp. 23, 24 y 33, y "La dimensión social de la globalización en los instrumentos de la OIT", op. cit., pp. 29, 30 y 35.

${ }^{85}$ Comisión Europea, Study on due diligence requirements through the supply chain, enero 2020, p. 243. Disponible en: https://op.europa.eu/en/publication-detail/-/publication/8ba0a8fd-4c83-11ea-b8b701aa75ed71a1/language-en

${ }^{86}$ DAUGAREILH, Isabelle, "Responsabilidad social...", op. cit., p. 80.

${ }^{87}$ VAN'T FOORT, Sander, op. cit., p. 210.

${ }^{88}$ LOI $n^{\circ}$ 2017-399 du 27 mars 2017 relative au devoir de vigilance des sociétés mères et des entreprises donneuses d'ordre. https://www.legifrance.gouv.fr/eli/loi/2017/3/27/ECFX1509096L/jo/texte

${ }^{89}$ NIETO ROJAS, Patricia, "Cadenas mundiales de suministro y trabajo decente: instrumentos jurídicos ordenados a garantizarlo”, Cuadernos de Relaciones Laborales, 2019, n 1, p. 424.
} 
las empresas ${ }^{90}$. En particular, su peculiar mecanismo de puesta en práctica -los PNCpueden servir de inspiración de cara a la creación de un órgano ad hoc en el ámbito de la Unión Europea que se encargue de hacer cumplir la debida diligencia por parte de las empresas.

\section{Bibliografía}

BLANPAIN, Roger, "Guidelines for Multinational Enterprises, for Ever? The OCDE Guidelines, 20 years later", The International Journal of Comparative Labour Law and Industrial Relations, 1998, vol. 14, nº 4, pp. 337-348.

BUENO, Nicolas, "Multinational enterprises and labour rights: concepts and implementation”, en BELLACE, Janice R., BLANK, Samuel, HAAR, Beryl ter, (Ed.), Research handbook on labour, business and human rights law, Reino Unido, Edward Elgar, 2019, pp. 421-438.

CANTÚ RIVERA, Humberto, "La OCDE y los derechos humanos: el caso de las Directrices para Empresas Multinacionales y los Puntos de Contacto Nacional", Anuario Mexicano de Derecho Internacional, 2015, vol. XV, pp. 611-658.

DAUGAREILH, Isabelle, "Responsabilidad social de las empresas transnacionales: análisis crítico y prospectiva jurídica”, Cuadernos de Relaciones Laborales, 2009, $\mathrm{n}^{\circ} 1$, pp. 77-106.

DAUGAREILH, Isabelle, "La dimension sociale des principes directeurs de l'O.C.D.E. à l'intention des entreprises multinationales", Revue générale de droit international public, 2008, vol. 112, no 3, pp. 567-599.

GIL Y GIL, José Luis, "Globalización y universalidad del derecho: la lex mercatoria y el derecho internacional del trabajo en el mercado global", Revista Internacional y Comparada de Relaciones Laborales y Derecho del Empleo, 2016, n² 2, 46-pp.

GIL Y GIL, José Luis, "La dimensión social de la globalización en los instrumentos de la OIT”, Revista Internacional y Comparada de Relaciones Laborales y Derecho del Empleo, 2017, $\mathrm{n}^{\mathrm{o}}$ 1, $54 \mathrm{pp}$.

\footnotetext{
${ }^{90}$ El pasado 29 de abril de 2020, el Comisario Europeo de Justicia, Didier Reynders, anunció que la Comisión se compromete a introducir reglas para la debida diligencia obligatoria corporativa sobre el medio ambiente y los derechos humanos. Véase: https://www.business-humanrights.org/es/comisario-de-justiciade-la-uni\%C3\%B3n-europea-se-compromete-con-legislaci\%C3\%B3n-sobre-la-debida-diligenciaobligatoria-para-empresas
} 
JIMÉNEZ SÁNCHEZ, José Joaquín, “Marcos de las relaciones laborales en las empresas multinacionales: las directrices de la OCDE”, Cuadernos de derecho judicial, 2005, $\mathrm{n}^{\circ}$ 17, pp. 15-212.

MURRAY, Jill, "A New Phase in the Regulation of Multinational Enterprises: The Role of the OECD”, Industrial Law Journal, 2001, vol. 30, nº 3, pp. 255-270.

NIETO ROJAS, Patricia, "Cadenas mundiales de suministro y trabajo decente: instrumentos jurídicos ordenados a garantizarlo", Cuadernos de Relaciones Laborales, 2019, no 1, pp. 419-434.

OLIVER, María Fabiana, GRUNAUER, Roque A., SERRANI, Esteban, Una herramienta de la RSE: Líneas Directrices de la OCDE, Buenos Aires, Fundación Ambiente y Recursos Naturales, 2006.

RUGGIE, John Gerard, Just business: multinational corporations and human rights, Nueva York, W. W. Norton \& Company, 2013.

SANER, Raymond, "Investment trends and OECD Guidelines for multinational enterprises (The Guidelines) and the United Nations guiding principles (UNGPS)", en BONUCCI, Nicola y KESSEDJIAN, Catherine, 40 Years of the OCDE Guidelines for Multinational Enterprises, París, Editions A. Pedone, 2018, pp. 157-163.

VAN'T FOORT, Sander, "The History of National Contact Points and the OECD Guidelines for Multinational Enterprises”, Rechtsgeschichte-Legal History, 2017, n 25, pp. 195-214.

WEBER, Rolf H., Development of coherent procedural rules for OECDE Guidelines' mediation, Draft background paper, Roundtable on Forty years of the OECD Guidelines for Multinational Enterprises, París, 19 diciembre 2016. Disponible en: http://mneguidelines.oecd.org/40-Years-OECD-Guidelines-2016-Background-

Paper1.pdf

\section{Anexo}

Comisión Europea, Study on due diligence requirements through the supply chain, enero 2020 , p. 243. Disponible en: https://op.europa.eu/en/publication-detail//publication/8ba0a8fd-4c83-11ea-b8b7-01aa75ed71a1/language-en

Ministerio de Economía y Competitividad, Guía de procedimiento para la resolución de casos específicos. Punto Nacional de Contacto de las Líneas Directrices de la OCDE para empresas multinacionales, 2015. Disponible en: http://www.comercio.mineco.gob.es/es- 
ES/inversiones-exteriores/punto-nacional-contacto-lineas-directrices/PDF/GuiaProcedimiento-PNC-15-11-20.pdf

OCDE, Progress report on National Contact Points for responsible business conduct, 2019. Disponible en: https://www.oecd.org/daf/inv/mne/progress-report-on-ncps-forresponsible-business-conduct-2019.htm

OCDE, Action Plan to Strengthen National Contact Points for Responsible Business Conduct 2019 - 2021. Disponible en:

https://mneguidelines.oecd.org/Action-Plan-to-Strengthen-National-Contact-Points-forResponsible-Business-Conduct-2019-2021.pdf

OCDE, Annual Report on the OECD Guidelines for Multinational Enterprises 2018, 2019.

Disponible en: https://www.oecd.org/daf/inv/mne/annualreportsontheguidelines.htm

OCDE, Implementing the OECD Guidelines for Multinational Enterprises: The National Contact Points from 2000 to 2015, 2016. Disponible en: https://mneguidelines.oecd.org/OECD-report-15-years-National-Contact-Points.pdf

OCDE, Lineas Directrices de la OCDE para Empresas Multinacionales, OECD Publishing, 2013.

Disponible en: http://dx.doi.org/10.1787/9789264202436-es

OCDE Watch, The State of Remedy under the OECD Guidelines. Understanding NCP cases concluded in 2018 through the lens of remedy, OECD Watch Briefing Paper, junio 2019. Disponible en: https://www.oecdwatch.org/2019/06/12/the-state-of-remedy-underthe-oecd-guidelines-understanding-ncp-cases-concluded-in-2018-through-the-lens-ofremedy/

OECD Watch, Remedy remains rare. An analysis of 15 years of NCP cases and their contribution to improve access to remedy for victims of corporate misconduct, junio 2015. Disponible en: https://www.oecdwatch.org/2015/06/01/remedy-remains-rare/

ONU, Principios Rectores sobre las empresas y los derechos humanos: puesta en práctica del marco de las Naciones Unidas para "proteger, respetar y remediar" Disponible en:

https://www.ohchr.org/documents/publications/guidingprinciplesbusinesshr_sp.pdf 